\title{
Dietary Requirement for Serum-Derived Bovine Immunoglobulins in the Clinical Management of Patients with Enteropathy
}

\author{
Bryon W. Petschow $\cdot$ Bruce P. Burnett • \\ Audrey L. Shaw • Eric M. Weaver • Gerald L. Klein
}

Received: 25 April 2014/Accepted: 4 August 2014/Published online: 21 August 2014

(C) The Author(s) 2014. This article is published with open access at Springerlink.com

\begin{abstract}
A variety of human disease conditions are associated with chronic intestinal disorders or enteropathies that are characterized by intestinal inflammation, increased gut permeability, and reduced capacity to absorb nutrients. Such disruptions in the homeostasis of the gastrointestinal (GI) tract can lead to symptoms of abdominal pain and discomfort, bloating, abnormal bowel function, and malabsorption of nutrients. While significant advances have been made in understanding the factors that influence the complex and fragile balance between the gut microbiota, intestinal epithelial cell integrity, and the underlying immune system, effective therapies for restoring intestinal balance during enteropathy are still not available. Numerous studies have demonstrated the ability of oral immunoglobulins to improve weight gain, support gut barrier function, and reduce the severity of enteropathy in animals. More recently, studies in humans provide evidence that serum-derived bovine immunoglobulin/protein isolate is safe and improves nutritional status and GI symptoms in patients with enteropathy associated with irritable bowel syndrome or infection with the human immunodeficiency virus. This review
\end{abstract}

\author{
B. W. Petschow $(\varangle) \cdot$ B. P. Burnett · A. L. Shaw · \\ E. M. Weaver - G. L. Klein \\ Entera Health, Inc., 2000 Regency Parkway, Suite 255, Cary, \\ NC 27518, USA \\ e-mail: bryon.petschow@enterahealth.com \\ B. P. Burnett \\ e-mail: bruce.burnett@enterahealth.com \\ A. L. Shaw \\ e-mail: audrey.shaw@enterahealth.com \\ E. M. Weaver \\ e-mail: eric.weaver@enterahealth.com \\ G. L. Klein \\ e-mail: gerald.klein@enterahealth.com
}

summarizes studies showing the impact of enteropathy on nutritional status and how specially formulated bovine immunoglobulins may help restore intestinal homeostasis and nutritional status in patients with specific enteropathies. Such protein preparations may provide distinct nutritional support required for the dietary management of patients who, because of therapeutic or chronic medical needs, have limited or impaired capacity to digest, absorb, or metabolize ordinary foodstuffs or certain nutrients, or other special medically determined nutrient requirements that cannot be satisfied by changes to the normal diet alone.

Keywords Immunoglobulins - Plasma proteins . Enteropathy · Gut barrier · Inflammation · Nutrition

\section{Introduction}

The unique structure of the intestinal epithelium provides both a vast surface area for nutrient absorption and a barrier mechanism that regulates the trafficking of macromolecules between the lumen of the intestine and the systemic circulation [1-3]. The effectiveness of the gut barrier is largely governed by intestinal permeability and mucosal immune defenses, the latter being provided mainly by the gut-associated lymphoid tissue (GALT). Permeation of solvents and solutes across the mucosal layer is closely regulated and mainly depends on the integrity of tight junction proteins (e.g., occludins, claudins) and scaffolding proteins that span the paracellular space [2]. Meanwhile, the lumen of the GI tract is occupied by a complex assortment of microbial species, the gut microbiota, which exists in a symbiotic relationship with the intestinal epithelium and mucus layer by providing protection against infection [3, 4], metabolizing dietary compounds and 
ingested foreign compounds (xenobiotics), and producing short chain fatty acids (SCFA) and other metabolites that support barrier function and energy metabolism.

Unfortunately, a variety of factors, both host-related and environmental, can disrupt intestinal homeostasis and lead to development of intestinal disorders or enteropathies. While the exact pathophysiologic mechanisms leading to enteropathy are not well understood, factors that appear to be involved include genetics, diet, alterations in the intestinal microbiota, host immune status, and exposure to external antigens, toxins, or other environmental insults (including infection). Such factors act singly or in combination to trigger changes in the intestinal mucosa or the gut microbiota that leads to a prolonged cycle of immune dysregulation, gut barrier dysfunction, and malabsorption of important macro- and micro-nutrients. Nutrient malabsorption is likely to play a pivotal role in amplifying and prolonging this cycle of events due to adverse effects on the health and function of gut epithelial and immune cells and the composition of the intestinal microbiota. Unique nutritional interventions that help manage this harmful cycle of events by improving nutrient absorption and nutritional status may represent a novel strategy to help restore functional gut homeostasis and manage enteropathy in patients.

It is well established that plasma-derived protein concentrates (PPC) from bovine, porcine, and other sources, when added to the diets of several species of animals, lead to improvements in appetite, weight gain, intestinal growth, and gut barrier function in a number of intestinal disorders [ 5 , 6]. More recently, preliminary studies with a serum-derived bovine immunoglobulin/protein isolate (SBI), specially formulated to increase immunoglobulin levels, have demonstrated promising results in the management of the enteropathy in patients with chronic loose and frequent stools in such conditions as diarrhea-predominant irritable bowel syndrome (IBS-D) and human immunodeficiency virus (HIV) infection as a medical food administered under physician supervision [7, 8]. This review summarizes current understanding about the impact of enteropathy on host nutritional status and how specially formulated immunoglobulin-containing protein preparations may support existing therapeutic strategies and fulfill a distinct nutritional requirement in patients with chronic intestinal disorders by helping to restore nutrient absorption and functional homeostasis in the GI tract, a requirement of medical foods. ${ }^{1}$

\section{Etiology and Clinical Features of Enteropathy}

The intestinal damage that is associated with enteropathy is typically characterized by blunting of intestinal villi, crypt

\footnotetext{
1 The Orphan Drug Act and Amendments of 1988 [21 U.S.C. $\S 360 \mathrm{ee}(\mathrm{b})(3)]$ and current FDA regulations/guidance.
}

hyperplasia, and increased intra-epithelial lymphocytes that leads to reduced absorptive capacity and increased gut permeability. The breakdown in intestinal barrier function can facilitate translocation of microbes or microbial components across the intestinal wall, leading to chronic systemic inflammation that may have additional adverse effects on patient health. Symptoms reported by patients with enteropathy vary depending on the etiologic factors involved, but commonly include chronic fatigue, abdominal pain, intestinal discomfort, nausea, bloating, and abnormal bowel function (e.g., acute or chronic diarrhea, urgency, constipation).

Perhaps the most widely recognized form of enteropathy is known as "environmental enteropathy," which refers to a spectrum of disorders that occurs in people living in unhygienic conditions [9]. Although the precise cause of environmental enteropathy is not known, it is thought to involve repeated, often subclinical episodes of GI infections which, together with suboptimal nutrition and altered intestinal microbiota, lead to chronic enteric T cell-mediated inflammation. Enteropathy can also occur following intake of nonsteroidal anti-inflammatory drugs (NSAIDS) through inhibition of cyclooxygenase (COX) activity or direct damage of epithelial cells or disruption of intercellular junctions, leading to increased mucosal permeability, antigen uptake, and immune activation $[10,11]$. Other important disease states or conditions where enteropathy commonly occurs include HIV infection [12, 13], irritable bowel syndrome (IBS) [14, 15], inflammatory bowel disease (IBD), celiac disease [16], and different forms of cancer or cancer treatment. A number of studies have reported that HIV-associated enteropathy and IBS, conditions associated with decreased barrier function, inflammatory damage, and malabsorption, where a causative pathogen cannot be identified, may involve dysregulation of GI motility, altered intestinal microbiota, immune activation, increased gut permeability, alterations in tryptophan metabolism, or the gut-brain axis [12-15, 17-19]. The enteropathy associated with these disease states affects a high percentage of patients and leads to incapacitating symptoms, low quality of life, and substantial healthcare costs. Unfortunately, truly effective therapeutic options aimed at the enteropathy associated with various disease states are not available, and recent attempts to launch new treatment options have been disappointing.

\section{Etiology of Enteropathy}

The pathophysiologic mechanisms leading to enteropathy are not well understood but may involve the effects of host diet or genetics, exposure to specific luminal antigens or toxins, dysregulated immune responses, or changes in the composition of the intestinal microbiota $[4,17,20]$. An 
Fig. 1 Enteropathy is associated with nutrient malabsorption caused by a persistent cycle of altered gut microbiota, immune imbalances, gut barrier dysfunction with altered permeability

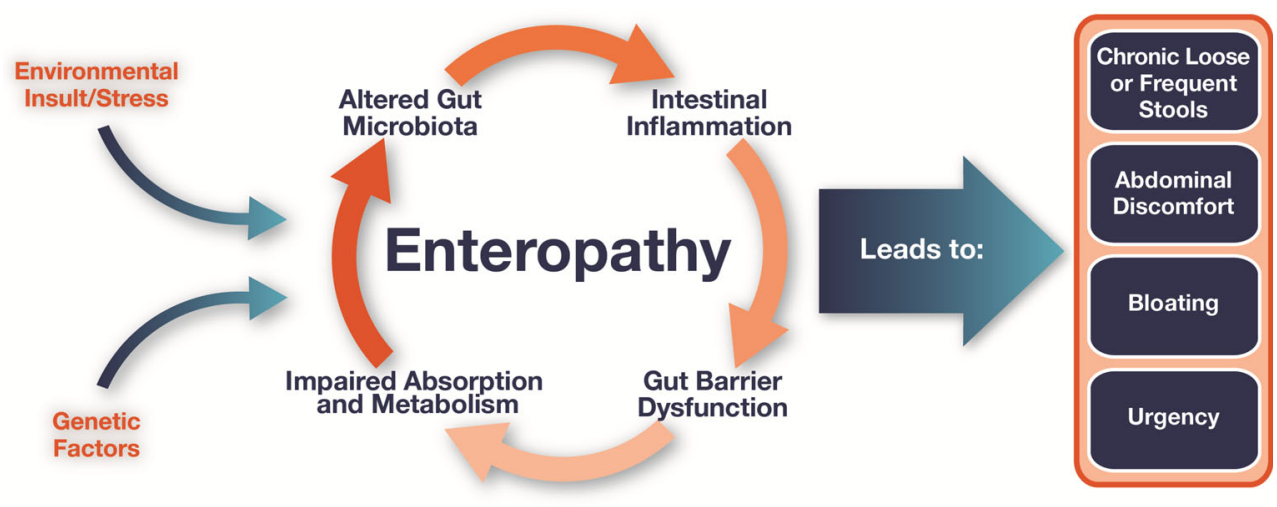

accumulating body of evidence from both preclinical and clinical studies indicates that such factors work individually or in combination to trigger a persistent cycle of altered gut microbiota, immune activation, leading to intestinal inflammation and gut barrier function that ultimately leads to malabsorption of important macro- and micro-nutrients (Fig. 1).

\section{Altered Gut Microbiota}

Alterations in the intestinal microbiota have been postulated to play a role in the etiology of enteropathy. For example, infectious gastroenteritis is accompanied by changes in GI microflora and immune activation and is widely recognized as a predisposing factor for IBS [21]. Postinfectious IBS occurs in 6-17\% of patients [22, 23]. Antibiotic use has also been recognized for a role in predisposing patients to IBS or exacerbating symptoms of IBS enteropathy [24]. Several studies have also reported differences in the composition of the intestinal microbiota in patients with IBS compared with healthy individuals [21, 25-27]. Likewise, the early phases of HIV infection have been associated with altered gut microbiota, damaged mucosal barrier, and intestinal inflammation [28]. Recent reports also suggest that levels of certain components of the resident microbiota are reduced in patients with chronic inflammatory disorders $[29,30]$ and may play a role in regulating inflammation and gut barrier function [31, 32]. For example, Akkermansia muciniphila, a mucin-degrading bacterium found in the mucus layer of healthy humans, has been associated with improvements in gut barrier function, metabolic profile, and decreases in endotoxemia [33]. Faecalibacterium prausnitzii, another purported beneficial commensal bacterium, was shown to be associated with increased production of IL-10 while significantly decreasing IL-12 and IFN- $\gamma$ in peripheral blood mononuclear cells [32]. Levels of $F$. prausnitzii are found in low abundance in patients with Crohn's Disease [34], colorectal cancer, and IBS [25], adding further support to its role as a beneficial commensal. Whether the dysbiosis observed in gut microbiota is a secondary phenomenon or truly causal in these diseases and conditions remains to be determined.

\section{Inflammation and Gut Barrier Dysfunction}

There is increasing evidence that the reciprocal effects of inflammation and gut barrier dysfunction play a role in the etiology of various human diseases or conditions that are associated with enteropathy [3, 17, 35]. For example, intestinal infections or other changes to the intestinal microbiota can cause aberrant or uncontrolled local immune responses that lead to transient or chronic inflammation, which is known to impact intestinal structure and function $[17,36]$ and may participate in the etiology of enteropathy. Intermittent or even minor inflammation can lead to increased production and release of pro-inflammatory interleukins and cytokines such as TNF- $\alpha$, IFN- $\gamma[1$, 37], which have been shown to affect intestinal function $[17,36]$ and increase paracellular permeability by impacting the expression or degradation of claudin and occludin tight junction proteins $[38,39]$. Conversely, certain anti-inflammatory cytokines such as IL-10 and TGF- $\beta$ appear to maintain tight junction barrier and protect against intestinal inflammation [1]. Other examples of disease states where molecular changes in tight junctions are believed to be associated with inflammation, diarrhea, and gut barrier dysfunction include chemotherapy during cancer [40] and IBS [37].

Alternatively, infections or exposure to other environmental factors can directly increase the porosity of the tight junction barrier. This increase in paracellular penetration of luminal substances leads to overexposure to pro-inflammatory antigens (e.g., intact bacteria, lipopolysaccharides, food antigens, xenobiotics) with associated release of proinflammatory cytokines and recruitment of inflammatory cells $[1,4,41]$ that can further exacerbate mucosal damage and gut permeability [42]. 


\section{Immune Dysregulation}

Recent evidence from genome-wide association studies in IBD support the hypothesis that certain genetic mutations may lead to inappropriate regulation of immune responses, which could impact gut barrier function and lead to enteropathy. For example, mutations that affect the function of certain pattern recognition receptors such as NOD2/ CARD15, expressed in immune cells with important functions in innate immunity, may result in defective down-regulation of pro-inflammatory cytokines that normally occurs during chronic NOD2 stimulation [43]. Other such genetic studies have shown associations between Crohn's disease and mutations in genes related to IL-10 [44], a potent anti-inflammatory cytokine, and IL-23 [45], a pro-inflammatory cytokine that serves as an important downstream mediator of inflammation.

\section{Impact of Enteropathy on Nutritional Status}

Alterations in gut barrier function, microbiota, and immune activation that occur during enteropathy can also lead to malabsorption of nutrients and, depending on severity, lead to chronic undernutrition. For example, an overzealous inflammatory response with local involvement of lymphocytes, mast cells, and neutrophils may result in the release of proteases, prostaglandins, leukotrienes, and other eicosanoids, and oxygen free radicals. These inflammatory mediators can impact the expression of nutrient transport proteins [46, 47], as well as tight junction proteins [1, 48], and cause microscopic damage which collectively leads to gut barrier dysfunction and malabsorption of water, electrolytes, and key nutrients. Altered bowel function (increased motility, diarrhea, etc.) during enteropathy can also impact nutritional status by interfering with absorption of vital nutrients and electrolytes or by causing changes in feeding patterns in an attempt to avoid symptoms. Acute or chronic malabsorption can lead to atypical vitamin levels, maldigestion or malabsorption of carbohydrates and fats, altered synthesis and reabsorption of bile acids, or abnormal metabolism of key amino acids like tryptophan, all of which can contribute further to symptoms. Stimulation of the immune system also shifts available energy and nutrients from growth and other productive functions and diverts them to support the immune system [49, 50].

The microscopic damage from inflammation or other environmental insults can also develop into macroscopic injury (erosions, ulcers, etc.) that appears histologically as villous blunting, crypt hyperplasia, or villous atrophy with inflammatory infiltrate. Enterocytes may be directly impacted through changes in cellular differentiation with compromised absorptive and secretory function. Deficiencies of brush border disaccharidases at the mucosal membrane may occur and lead to maldigestion and intolerance to various dietary sugars. Disaccharide malabsorption can lead to bacterial fermentation with production of SCFAs and gas and changes in the composition of the microbiota, contributing further to symptoms [51]. Injury of enterocytes may alter gut permeability and predispose to development of a protein-losing enteropathy. Moreover, bacteria may compete with the host for protein and lead to the production of ammonia [52]. Deconjugation of bile acids in the proximal gut causes malabsorption of fat and lipophilic vitamins (A, $\mathrm{D}, \mathrm{E})$ and leads to the production of lithocholic acid, which is poorly absorbed and may be directly toxic to enterocytes [53]. While the impact of nutrients on gut epithelial function is not completely understood, it is possible that malabsorption of specific nutrients can compromise the ability to overcome the intestinal damage that occurs with enteropathy.

Host genetics can also impact the efficiency of nutrient processing that occurs in individuals with disease states associated with enteropathy. Dozens of mutated gene loci, for example, have been implicated in IBS [54] with possible effects on intestinal permeability, tryptophan metabolism [18], or the synthesis and metabolism of bile acids [55]. Modifications in tryptophan, serotonin, and bile acid metabolism, as well as alterations in the host microbiome, have been implicated in causing or exacerbating many of the symptoms associated with IBS-D [18, 19]. Likewise, perturbations in the intestinal microflora that occur in disease states with enteropathy also have the ability to impact host nutritional status including fluid balance. Both diet and alterations in the microbiota can impact luminal concentration of intestinal SCFAs [56], which act as an energy source for the host, exert effects on the cytokine production profile of helper T cells [57], and promote intestinal epithelial barrier function $[58,59]$. The intestinal microbiota can synthesize several vitamins that play important roles in microbial and host metabolism, including cobalamin (vitamin B12), vitamin B6, pantothenic acid (vitamin B5), niacin (vitamin B3), biotin, tetrahydrofolate, and vitamin $\mathrm{K}$. The microbiota also affects the absorption of key minerals such as iron, which serves as an essential micronutrient for bacteria and impacts immune functions. Finally, small intestinal bacterial overgrowth (SIBO) can interfere with the metabolism and absorption of carbohydrates, proteins, lipids, and vitamins because of increased levels of bacteria in the small intestine.

Clearly, exposure to noxious environmental factors that lead to the changes in the gut microbiota or mucosal lining associated with enteropathy can also impact functional digestion and absorption of key nutrients important for supporting health and recovery from disease. Patients with enteropathy may have a distinct nutritional requirement for 
a specially formulated dietary compound that restores functional homeostasis in the gut by managing the chronic impact of gut barrier dysfunction, altered intestinal microbiota, or dysregulated mucosal immune activation.

\section{Dietary Requirement for Oral Immunoglobulins to Manage Enteropathy}

Colostrum and breast milk, the sole source of nutrition for the neonate, contain immunoglobulins as well as a number of important bioactive factors and nutrients. Such factors, along with early exposure to external antigens and bacteria, are critical for providing passive protection from infections, establishing the intestinal microbiota, and stimulating maturation of the infant's mucosal immune system [60-62]. Immunoglobulins play a particularly prominent role in providing the gastrointestinal health and developmental benefits of human milk and colostrum, along with other factors such as regulatory cytokines, growth factors, lysozyme, lactoferrin, and oligosaccharides [60]. A large body of evidence also indicates that serum- or plasma-derived bovine immunoglobulin preparations fulfill a similar nutritional need by helping to manage the harmful effects of enteropathy by promoting gut homeostasis [5-8, 66, 67].

\section{Safety and Nutritive Benefits of Oral Immunoglobulins}

The recognition that colostrum is essential for the health and early survival of ruminant neonates led to the development of commercial plasma-derived protein concentrates which contain immunoglobulins that have been used for decades in animal husbandry to promote growth, prevent infections, and modulate intestinal inflammation in young immune-compromised animals. Numerous studies have evaluated the safety and nutritive benefits of commercial serum or plasma protein preparations in piglets undergoing early weaning, a condition known to induce impairment in intestinal epithelial barrier function, as well as several preclinical models of intestinal inflammation (Table 1). A review of 75 nonclinical studies in 43 different publications [6] indicates that bovine immunoglobulin-containing protein concentrates (PPC's) are safe and improve appetite, weight gain, and intestinal barrier function in weaning pigs. Replacement of several high-quality protein sources (e.g., meat extracts, soy, pea, and potato protein isolates, skimmed milk, whey protein, fishmeal) with immunoglobulin protein mixtures similar to the composition of SBI led to superior weight gain and feed intake in weaned piglets, suggesting that distinct proteins in SBI were involved in stimulating beneficial digestive and metabolic effects [5]. Nonclinical studies have found that as much as $50 \%$ of IgG from SBI survives transit through the stomach, while
5-10\% survives transit through the entire intestinal tract $[63,64]$.

The safety and nutritive benefits of oral immunoglobulins have also been evaluated in clinical studies involving both pediatric and adult subjects using a commercial form of $\mathrm{SBI}^{2}$ that contains over $90 \%$ protein (by weight), over $50 \%$ of which are immunoglobulins, (mainly IgG). The remaining proteins and peptides reflect the composition of plasma and are similar to proteins present in colostrum and milk, and the preparation does not contain milk ingredients such as lactose, casein, or whey, so adverse reaction rates would be expected to be minimal. However, SBI contains beef proteins, so patients who have an allergy to beef should not take SBI. The rigorous process used to prepare commercial forms of SBI meets strict industry standards of current good manufacturing practices (cGMPs) to ensure that finished products do not become contaminated with infectious agents, including the bovine spongiform encephalitis (BSE) agent. In addition, SBI has been selfaffirmed as generally recognized as safe (GRAS) with no safety-related questions by the US Food and Drug Administration (FDA) for doses up to $50 \mathrm{~g} / \mathrm{d}$. SBI has not yet been tested in pregnant or nursing mothers or immunocompromised individuals, so use in such patients should be at the discretion of the patients' physician.

In a human study of SBI tolerability and digestion, intact bovine IgG was detected in the feces of volunteers but not serum $(n=12)$, providing evidence that bovine immunoglobulin is not absorbed from the intestinal lumen into the circulation [65]. Volunteers were administered $10 \mathrm{~g}$ of SBI orally and blood samples were obtained at various time points, which showed elevated plasma levels of total amino acids and leucine from 1 to $2 \mathrm{~h}$ after SBI administration. This suggests at least partial digestion of the protein mixture to the amino acid level during transit through the intestine. Survival of the bovine IgG fraction through the GI tract suggests that oral SBI remains biologically active to manage chronic loose and frequent stools in conditions such as IBS-D and HIV-associated enteropathy. Subjects then consumed $5 \mathrm{~g}$ of SBI daily for 2 weeks and completed daily diaries for general health and adverse events (AEs). No serious AEs were reported by test subjects. The following AEs were reported: increased urination (3); stomach cramps (3); fatigue (2); headache (2); sore throat, softened stools, nausea, constipation, and irritability (1 each) [65].

In a randomized and controlled, community-based intervention study, the effects of dietary supplementation

\footnotetext{
${ }^{2}$ EnteraGam is a serum-derived bovine immunoglobulin/protein isolate (SBI) specially formulated for use as a medical food to be used under medical supervision for patients with limited or impaired capacity to ingest, digest, absorb, or metabolize ordinary foods or certain nutrients because of therapeutic or chronic medical needs and for management of chronic loose and frequent stools.
} 
Table 1 Effects of serum-derived immunoglobulin preparations on intestinal barrier function and immune response

\begin{tabular}{|c|c|c|c|}
\hline Species & Model/Indication & Impact of dietary administration of immunoglobulin preparations & References \\
\hline Pig & Post-weaning & $\begin{array}{l}\text { Reduced TNF- } \alpha \text { in the colon } \\
\text { Reduced IFN } \gamma \text { levels in the ileum and colon day } 7 \text {, but not day } 14 \text { PW }\end{array}$ & $\begin{array}{l}\text { Peace et al. } \\
\text { [68] }\end{array}$ \\
\hline \multirow[t]{3}{*}{ Pig } & Post-weaning & $\begin{array}{l}\text { Reduced colonic paracellular permeability } \\
\text { Reduced ileal permeability } \\
\text { Fewer lamina propria cells in ileum and colon } \\
\text { Reduced transepithelial electrical resistance in the colon-improved tight junction } \\
\text { Significantly improved fecal scores }\end{array}$ & $\begin{array}{l}\text { Peace et al. } \\
{[68]}\end{array}$ \\
\hline & Rotavirus infection & $\begin{array}{l}\text { Significantly reduced clinical signs of diarrhea } \\
\text { Significantly greater intestinal mucosal protein and lactase activity }\end{array}$ & Corl et al. [70] \\
\hline & Infection by ETEC K88 & $\begin{array}{l}\text { Reduced expression of TNF- } \alpha \text { and IL- } 8 \text { in the gut } \\
\text { Decreased inflammatory cell infiltration and mucosal damage } \\
\text { Increased crypt depth, reduced intestinal expression of proinflammatory TNF- } \alpha \\
\text { and IL- } 8\end{array}$ & Bosi et al. [71] \\
\hline Rat & Exposure to SEB & $\begin{array}{l}\text { Improved ion transport function, as measured by reductions in the potential } \\
\text { difference across the jejunum and Na-K-ATPase activity } \\
\text { Improved mucosal permeability (dextran flux and HRP paracellular flux) }\end{array}$ & $\begin{array}{l}\text { Perez-Bosque } \\
\text { et al. [48] }\end{array}$ \\
\hline Rat & SEB & $\begin{array}{l}\text { Prevented the SEB-induced increase in IFN } \gamma \text {, IL- } 6 \text {, and } \mathrm{LTB}_{4} \text { in Peyer's patches } \\
\text { and in the mucosa } \\
\text { Increased anti-inflammatory cytokines (IL-10 and mature TGF } \beta \text { ) in intestinal } \\
\text { mucosa } \\
\text { Reduced SEB-induced increase in cytotoxic lymphocyte populations of } \gamma \delta \text {-T } \\
\text { cells, natural killer cells, and the number of activated T lymphocytes in lamina } \\
\text { propria }\end{array}$ & $\begin{array}{l}\text { Perez-Bosque } \\
\text { et al. [74] }\end{array}$ \\
\hline Mouse & $\begin{array}{l}\text { Mdr1-/- knockout mouse model } \\
\text { of spontaneous colitis }\end{array}$ & $\begin{array}{l}\text { Reduced the percentage of activated Th lymphocytes } \\
\text { Reduced INF } \gamma \text { and TNF } \alpha \text { expression in the colon } \\
\text { Significantly reduced the expression of cytokines IL- } 2 \text { and IL-17, chemokines } \\
\text { MCP-1 and MIP-1b, and iNOS in the mucosa }\end{array}$ & $\begin{array}{l}\text { Moretóet al. } \\
\text { [72] }\end{array}$ \\
\hline Mouse & $2 \%$ DSS-induced IBD model & Reduced elevation of IL-1 $\alpha$, IL-4, IL-6, IL-10, MCP-1, and KC & $\begin{array}{l}\text { Jiang et al. } \\
\text { [73] }\end{array}$ \\
\hline
\end{tabular}

TNF $\alpha$ tumor necrosis factor $\alpha, I F N \gamma$ interferon- $\gamma$, ETEC K88 enterotoxigenic Escherichia coli $\mathrm{K} 88$ strain, IL-8 interleukin-8, SEB Staphylococcus aureus enterotoxin B, Na-K-ATPase sodium-potassium adenosine triphosphatase, HRP horse radish peroxidase, IL-6 interleukin-6, LTB4 leukotriene B4, $I L-10$ interleukin-10, TGF $\beta$ transforming growth factor $\beta, I L-17$ interleukin $17, M C P-1$ monocyte chemotactic protein $1, M I P-1 b$ macrophage inflammatory protein, $i N O S$ inducible nitric oxide synthase, $D S S$ dextran sodium sulfate, $I L-1 \alpha$ interleukin- $1 \alpha, I L-4$ interleukin-4, $K C$ keratinocyte-derived cytokine

with bovine serum concentrate $(22 \% \mathrm{IgG}, \mathrm{w} / \mathrm{w})$ and/or multiple micronutrients (MMN) on growth, morbidity, and micronutrient status were evaluated in healthy children [66]. Children were enrolled at 6 to 7 months of age $(n=259)$ and randomized to receive 1 of 4 maize-based study products daily for up to 8 months: whey protein concentrate WPC (control group), bovine serum concentrate (BSC), WPC plus multiple micronutrients, or BSC plus multiple micronutrients. One hundred thirty-two children $(132 ; 51.0 \%)$ finished the full 8 months of study observation. There were no significant differences reported in the rate of dropouts between treatment groups during the study and the rate of early dropouts did not correlate with study product consumed or prevalence/incidence of morbidity. While not significant, trends were observed for improvements in weight gain and lean body mass.
In another study, the acceptability, safety, and digestibility of spray-dried bovine plasma proteins including immunoglobulins were evaluated in young Peruvian children (9-25 months of age) recovering from severe proteinenergy malnutrition [67]. A control diet prepared from rice, milk, vegetable oil, and sugar was compared with 2 study diets where a bovine plasma protein mixture replaced either 25 or $50 \%$ of the milk protein in the control diet. Fractional absorption of dietary lipid and of total energy increased significantly in relation to the amount of SBI in the diet, as shown by decreased fecal fat and energy content. Diets containing greater amounts of plasma protein mixture with immunoglobulins and reduced levels of milk protein led to progressive reductions in wet and dry stool weights and greater fat absorption compared with the control diet, leading authors to suggest that the plasma 
protein mixtures were more digestible or enhanced recovery from malnutrition. There was also a trend toward superior nitrogen and carbohydrate absorption with increasing amounts of plasma protein.

\section{Ability to Restore Functional Homeostasis of the Gut Barrier}

The ability of serum protein preparations like SBI to restore intestinal barrier function and nutrient absorption, or essentially functional homeostasis, has been evaluated in a number of preclinical studies (Table 1). Studies using animal models and ex vivo test systems have evaluated tight junction protein expression in the epithelial barriers of early-weaned piglets fed diets containing porcine plasma protein with high levels of immunoglobulins [68]. Intestinal barrier function was shown to be improved in piglets fed diets containing porcine plasma protein as indicated by an increased transepithelial electrical resistance and significant reductions in colonic ${ }^{14} \mathrm{C}$-inulin permeability on day 7 post-weaning and reduced ileal permeability of ${ }^{3} \mathrm{H}$ mannitol and ${ }^{14} \mathrm{C}$-inulin on day 14 [68]. Immunofluorescence staining demonstrated that claudin-1 was more highly expressed and localized to tight junctions in animals fed porcine plasma protein, compared with the diffuse lowsignal staining observed in control tissues at 7-day postweaning [68]. Other studies have demonstrated the ability of plasma protein preparations to directly improve gut permeability, prevent antigen translocation across damaged tight junctions via direct binding and steric hindrance, and have an impact on tight junction protein expression [48, 69]. Together, these studies demonstrate that serum protein preparations containing immunoglobulins are able to manage the negative effects of antigen/toxin challenge on the intestinal epithelial barrier.

The impact of SBI on markers of intestinal absorption, GI symptom scores, and quality of life measures have also been evaluated in two clinical studies involving patients with HIV-associated enteropathy or IBS-D. In an open label study by Asmuth et al. [8], eight subjects with HIVassociated enteropathy showed improvements in GI symptoms with reduced bowel movements per day $(p<0.008)$ and improvements in stool consistency $(p<0.008)$. Seven of the eight subjects also showed increased uptake of D-xylose suggesting improved absorption of nutrients. Another randomized, doubleblind, placebo-controlled study was conducted in subjects with IBS-D [7] to investigate the impact of SBI on improving gastrointestinal (GI) symptom scores and quality of life (QoL). Study subjects consuming SBI reported a significant decrease in the number of days with GI symptoms (e.g., abdominal pain, flatulence, bloating, urgency, and loose stools), suggesting improved GI function with implications for nutritive benefits. Soy protein administered at the same dose did not statistically improve any GI symptoms. These results demonstrate that $\mathrm{SBI}$, a specially formulated bovine IgG protein preparation, provides for a distinct nutritional requirement in enteropathy patients who have a limited or impaired capacity to ingest, digest, absorb, or metabolize ordinary foodstuffs or certain nutrients, and those with fluid imbalance due to chronic loose and frequent stools (i.e., IBS-D and HIV-associated enteropathy).

\section{Impact on Immune Balance}

Studies on the effects of bovine immunoglobulin isolates (PPC or SBI) on inflammation in the GI tract have primarily come from preclinical models in which animals were challenged by infection or exposure to bacterial toxins (Table 1). For example, Corl et al. [70] found PPC to be effective at reducing diarrhea, improving intestinal recovery and maintaining growth in piglets infected with rotavirus. Bosi et al. [71] investigated the impact of PPC on growth and intestinal inflammation in pigs challenged with enterotoxigenic Escherichia coli K88 (ETEC K88). When compared to a diet based on fish protein, pigs infected with ETEC K88 and fed PPC showed higher calorie intake and daily weight gain, less intestinal mucosal damage (ulceration, edema) and inflammatory cell infiltration, and reduced expression of pro-inflammatory cytokines. Oral SBI has also been shown to reduce the expression of pro-inflammatory cytokines (e.g., TNF- $\alpha$, IL-6) and alter the lymphocyte response of immune challenge in weaned piglets [68], and experimental models of intestinal inflammation in mice [72, 73], rats [74, 75], and pigs [71]. These results from experimental studies suggest that dietary PPC provides anti-inflammatory effects that benefits recovery of intestinal barrier function.

In the trial involving patients with HIV-associated enteropathy mentioned earlier, SBI significantly increased mucosal CD4+ lymphocyte densities over 8 wks, but had no effect on circulating CD4+ counts [8]. In addition, a marker for enterocyte damage, intestinal fatty acid protein (I-FABP), initially rose in $7 / 8$ subjects after 8 weeks, but then fell below baseline in $4 / 5$ subjects who continued taking SBI for 40 additional weeks, suggesting that inflammation-based destruction of enterocytes had been ameliorated. Monocyte chemoattractant protein-1 (MCP-1) levels were also negatively correlated with lamina propria CD4+ density, suggesting a commonality of systemic inflammation and mucosal immunity. In addition, inflammation-induced tissue remodeling matrix metallo-proteinases decreased over time also suggesting a dampening of inflammation and tissue-specific remodeling in the intestine. 
Effects on Microbiota Balance and Endotoxin Binding

Immunoglobulins may also impart the nutritive benefits of SBI by impacting the growth and maintenance of the normal intestinal microbiota. Because SBI is prepared from pooled plasma obtained from thousands of bovine donors, the immunoglobulins in SBI are directed at a wide array of foreign antigens and microbial organisms. This includes IgG that is specific for highly conserved microbial antigens that allows direct binding to microbial cell wall or other microbial components and interferes with their ability to enter or damage intestinal epithelial cells. Studies have shown that the $\operatorname{IgG}, \operatorname{IgA}$, and IgM contained in SBI bind to bacterial endotoxins and other microbial antigens [76, 77]. It is possible that binding of endotoxins or other proinflammatory antigens may interfere with the signaling mechanisms on innate immune cells and prevent downstream signaling cascades that lead to production of proinflammatory cytokines and inflammation.

The effect of SBI on restoring imbalances of microbiota was also studied in patients with HIV-associated enteropathy [78, 79]. While Firmicutes and Bacteriodales were found to be the dominant phyla in stool samples of all 8 $\mathrm{HIV}+$ patients, when SBI was administered, pro-inflammatory gammaproteobacteria tended to decrease from levels of 0.70 to $0.12 \%$ [78]. Clostridium spp. tended to decrease from 6.5 to $3.4 \%$ in stool and correlated with duodenal CD3+/CD4+ density $(r=-0.63 ; p<0.01)$. Ruminococcus spp. and the Bacteroidetes/Firmicutes ratio also increased in 6/8 subjects, an effect that has been implicated in contributing to better calorie utilization from the diet $[80,81]$. These results suggest that some component in SBI, perhaps the IgG fraction, may be effective in normalizing gut bacteria with potential implications for improving nutrient utilization.

\section{Conclusions}

Most therapies that are currently used in patients with enteropathy are aimed at lessening symptoms rather than managing the underlying causes of the disorder. This may be due to the complex mechanisms involved in the pathophysiology of enteropathy, which may serve to explain why no single treatment has been shown to be effective in patients with enteropathy. A variety of preclinical studies and clinical trials have demonstrated that special formulations of serum-derived immunoglobulin/protein isolates (SBI) improve nutritional status, support gut barrier function, and manage enteropathy. Immunoglobulins appear to be unique, compared with multiple other protein sources, in terms of providing distinctive nutrition required to manage enteropathy in these studies. Possible ways that oral
Table 2 Potential roles for how oral immunoglobulins may contribute to protection of mucosal surfaces and maintaining intestinal homeostasis

\begin{tabular}{|c|c|c|}
\hline Mechanism & Action & Host benefit \\
\hline \multirow[t]{2}{*}{$\begin{array}{l}\text { Immune } \\
\text { exclusion }\end{array}$} & $\begin{array}{l}\text { Binding to multiple } \\
\text { antigenic epitopes on } \\
\text { bacterial surfaces or } \\
\text { toxins to avoid } \\
\text { interaction with } \\
\text { epithelial surfaces; } \\
\text { complexes excreted } \\
\text { by peristaltic removed } \\
\text { from GI tract }\end{array}$ & $\begin{array}{l}\text { Passive protection by } \\
\text { decreasing viability or } \\
\text { virulence of microbial } \\
\text { pathogens (e.g., } \\
\text { altering outer } \\
\text { membrane } \\
\text { permeability, } \\
\text { motility) or toxins and } \\
\text { interfering with the } \\
\text { ability of pathogens to } \\
\text { bind to intestinal } \\
\text { mucosal surfaces and } \\
\text { cause damage or } \\
\text { inflammatory } \\
\text { responses }\end{array}$ \\
\hline & $\begin{array}{l}\text { Binding to specific pro- } \\
\text { inflammatory } \\
\text { antigens, microbial } \\
\text { cell surface } \\
\text { components (e.g., } \\
\text { LPS, peptidoglycan, } \\
\text { etc.) or foreign } \\
\text { proteins }\end{array}$ & $\begin{array}{l}\text { Avoiding epithelial } \\
\text { damage caused by } \\
\text { inflammatory } \\
\text { responses that occur } \\
\text { in response to LPS, } \\
\text { etc. in the lamina } \\
\text { propria }\end{array}$ \\
\hline $\begin{array}{l}\text { Shaping the gut } \\
\text { microbiota }\end{array}$ & $\begin{array}{l}\text { Binding to specific cell } \\
\text { surface components of } \\
\text { commensal bacteria }\end{array}$ & $\begin{array}{l}\text { Potential roles include } \\
\text { influencing microbial } \\
\text { gene expression or } \\
\text { regulating } \\
\text { development of } \\
\text { protective (or } \\
\text { tolerogenic) immune } \\
\text { responses to } \\
\text { pathogens or } \\
\text { commensal bacteria }\end{array}$ \\
\hline $\begin{array}{l}\text { Protection of } \\
\text { damaged or } \\
\text { inflamed } \\
\text { epithelium }\end{array}$ & $\begin{array}{l}\text { Binding and } \\
\text { neutralizing potential } \\
\text { pathogens that have } \\
\text { penetrated tight } \\
\text { junctions and/or gain } \\
\text { access to the lamina } \\
\text { propria in damaged or } \\
\text { inflamed epithelium }\end{array}$ & $\begin{array}{l}\text { Neutralization of } \\
\text { microbial pathogens } \\
\text { or creating antigen } \\
\text { complexes that are } \\
\text { more readily handled } \\
\text { by local immune } \\
\text { systems }\end{array}$ \\
\hline $\begin{array}{l}\text { Influence local } \\
\text { immune } \\
\text { trafficking }\end{array}$ & $\begin{array}{l}\text { Interaction between } \\
\text { specific antibody } \\
\text { complexes and } \\
\text { various immune cells } \\
\text { (e.g., M cells, } \\
\text { dendritic cells) to } \\
\text { influence } \\
\text { inflammatory } \\
\text { responses, regulatory } \\
\mathrm{T} \text { cells, etc. }\end{array}$ & $\begin{array}{l}\text { Neutralize pro- } \\
\text { inflammatory } \\
\text { bacterial cell wall } \\
\text { components (e.g., } \\
\text { lipopolysaccharides, } \\
\text { peptidoglycan), down- } \\
\text { regulate inflammatory } \\
\text { processes, etc. }\end{array}$ \\
\hline
\end{tabular}

immunoglobulins might work to restore gut homeostasis during enteropathy include "immune exclusion" to prevent contact between bacteria or bacterial components and gut epithelium or immune cells, shaping the gut microbiota, or 
modulating immune responses and mucosal damage [82] (Table 2).

Specially formulated immunoglobulin sources like SBI appear to act through a multifaceted mode of action that serves to bind and neutralize pro-inflammatory microbial components, support a beneficial gut microbiota, manage gut barrier function, and maintain immune balance. These effects collectively serve to improve and maintain nutrient utilization, including water balance, to aid in the management of enteropathy in patients with chronic loose and frequent stools in conditions like IBS-D and HIV-infected patients. Taken together, results from clinical and nonclinical studies with SBI reveal a distinct nutritional requirement for immunoglobulins for the purpose of restoring functional homeostasis to aid in the management of enteropathy.

Acknowledgments B.W.P and B.P.B. wrote the paper; A.L.S. and E.W. reviewed the paper; G.L.K. had primary responsibility for final content. All authors read and approved the final manuscript.

Conflict of interest All authors are employed by Entera Health, Inc.

Open Access This article is distributed under the terms of the Creative Commons Attribution Noncommercial License which permits any noncommercial use, distribution, and reproduction in any medium, provided the original author(s) and the source are credited.

\section{References}

1. Al-Sadi R, Boivin M, Ma T. Mechanism of cytokine modulation of epithelial tight junction barrier. Front Bbiosci. 2009;14:27652778.

2. Kotler BM, Kerstetter JE, Insogna KL. Claudins, dietary milk proteins, and intestinal barrier regulation. Nutr Rev. 2013;71:60-65.

3. Farhadi A, Banan A, Fields J, Keshavarzian A. Intestinal barrier: an interface between health and disease. J Gastroenterol Hepatol. 2003;18:479-497.

4. Natividad JM, Verdu EF. Modulation of intestinal barrier by intestinal microbiota: pathological and therapeutic implications. Pharmacol Res. 2013;69:42-51.

5. Coffey RD, Cromwell GL. Use of spray-dried animal plasma in diets for weanling pigs. Pig News Inf. 2001;22:39N-48N.

6. Torrallardona D. Spray dried animal plasma as an alternative to antibiotics in weanling pigs-a review. Asian-Australasian $J$ Anim Sci. 2010;23:131-148.

7. Wilson D, Evans MD, Weaver E, et al. Evaluation of serumderived bovine immunoglobulin protein isolate in subjects with diarrhea-predominant irritable bowel syndrome. Clin Med Insights Gastroenterol. 2013;6:49-60.

8. Asmuth DM, Ma ZM, Albanese A, et al. Oral serum-derived bovine immunoglobulin improves duodenal immune reconstitution and absorption function in patients with HIV enteropathy. AIDS. 2013;27:2207-2217.

9. Prendergast A, Kelly P. Enteropathies in the developing world: neglected effects on global health. Am J Trop Med Hyg. 2012;86:756-763.

10. Higuchi K, Umegaki E, Watanabe T, et al. Present status and strategy of NSAIDs-induced small bowel injury. J Gastroenterol. 2009;44:879-888.
11. Sostres C, Gargallo CJ, Arroyo MT, Lanas A. Adverse effects of non-steroidal anti-inflammatory drugs (NSAIDs, aspirin and coxibs) on upper gastrointestinal tract. Best Pract Res Clin Gastroenterol. 2010;24:121-132.

12. Sharpstone D, Neild P, Crane R, et al. Small intestinal transit, absorption, and permeability in patients with AIDS with and without diarrhoea. Gut. 1999;45:70-76.

13. Sankaran S, George MD, Reay E, et al. Rapid onset of intestinal epithelial barrier dysfunction in primary human immunodeficiency virus infection is driven by an imbalance between immune response and mucosal repair and regeneration. $J$ Virol. 2008;82:538-545.

14. Camilleri M, Madsen K, Spiller R, et al. Intestinal barrier function in health and gastrointestinal disease. Neurogastroenterol Motil. 2012;24:503-512.

15. Gasbarrini A, Lauritano EC, Garcovich M, et al. New insights into the pathophysiology of IBS: intestinal microflora, gas production and gut motility. Eur Rev Med Pharmacol Sci. 2008;12:111-117.

16. Schuppan D, Junker Y, Barisani D. Celiac disease: from pathogenesis to novel therapies. Gastroenterology. 2009;137:1912-1933.

17. Matricon J, Meleine M, Gelot A, et al. Review article: associations between immune activation, intestinal permeability and the irritable bowel syndrome. Aliment Pharmacol Therapeut. 2012;36:1009-1031.

18. Keszthelyi D, Troost FJ, Masclee AA. Understanding the role of tryptophan and serotonin metabolism in gastrointestinal function. Neurogastroenterol Motil. 2009;21:1239-1249.

19. Simren M, Barbara G, Flint HJ, et al. Intestinal microbiota in functional bowel disorders: a Rome foundation report. Gut. 2013;62:159-176.

20. Fasano A, Shea-Donohue T. Mechanisms of disease: the role of intestinal barrier function in the pathogenesis of gastrointestinal autoimmune diseases. Nat Clin Pract Gastroenterol Hepatol. $2005 ; 2: 416-422$.

21. Jalanka-Tuovinen J, Salojarvi J, Salonen A, et al. Faecal microbiota composition and host-microbe cross-talk following gastroenteritis and in postinfectious irritable bowel syndrome. Gut. 2013.

22. Ohman L, Simren M. Pathogenesis of IBS: role of inflammation, immunity and neuroimmune interactions. Nat Rev Gastroenterol Hepatol. 2010;7:163-173.

23. Spiller R, Garsed K. Infection, inflammation, and the irritable bowel syndrome. Digest Liver Dis. 2009;41:844-849.

24. Pimentel M, Park S, Mirocha J, et al. The effect of a nonabsorbed oral antibiotic (rifaximin) on the symptoms of the irritable bowel syndrome: a randomized trial. Ann Intern Med. 2006;145:557563.

25. Rajilic-Stojanovic M, Biagi E, Heilig HG, et al. Global and deep molecular analysis of microbiota signatures in fecal samples from patients with irritable bowel syndrome. Gastroenterology. 2011;141:1792-1801.

26. Carroll IM, Ringel-Kulka T, Keku TO, et al. Molecular analysis of the luminal- and mucosal-associated intestinal microbiota in diarrhea-predominant irritable bowel syndrome. Am J Physiol Gastrointest Liver Physiol. 2011;301:G799-G807.

27. Jeffery IB, O'Toole PW, Ohman L, et al. An irritable bowel syndrome subtype defined by species-specific alterations in faecal microbiota. Gut. 2012;61:997-1006.

28. Gori A, Tincati C, Rizzardinin G, Torti C. Early impairment of gut function and gut flora supporting a role for alteration of gastrointestinal mucosa in human immunodeficiency virus pathogenesis. J Clin Microbiol. 2008;46:757-758.

29. Marchesi JR, Holmes E, Khan F, et al. Rapid and noninvasive metabonomic characterization of inflammatory bowel disease. $J$ Proteome Res. 2007;6:546-551. 
30. Lidar M, Langevitz P, Shoenfeld Y. The role of infection in inflammatory bowel disease: initiation, exacerbation and protection. Isr Med Assoc J. 2009;11:558-563.

31. Cho I, Blaser MJ. The human microbiome: at the interface of health and disease. Nat Rev Genet. 2012;13:260-270.

32. Sokol H, Pigneur B, Watterlot L, et al. Faecalibacterium prausnitzii is an anti-inflammatory commensal bacterium identified by gut microbiota analysis of Crohn disease patients. Proc Natl Acad Sci USA. 2008;105:16731-16736.

33. Everard A, Belzer C, Geurts L, et al. Cross-talk between Akkermansia muciniphila and intestinal epithelium controls dietinduced obesity. Proc Natl Acad Sci USA. 2013;110:9066-9071.

34. Sokol H, Seksik P, Furet JP, et al. Low counts of Faecalibacterium prausnitzii in colitis microbiota. Inflamm Bowel Dis. 2009; 15:1183-1189.

35. Hartnett L, Egan LJ. Inflammation, DNA methylation and colitisassociated cancer. Carcinogenesis. 2012;33:723-731.

36. Peuhkuri K, Vapaatalo H, Korpela R. Even low-grade inflammation impacts on small intestinal function. World $J$ Gastroenterol. 2010;16:1057-1062.

37. Camilleri M. Peripheral mechanisms in irritable bowel syndrome. N Engl J Med. 2012;367:1626-1635.

38. Cummins PM. Occludin: one protein, many forms. Mol Cell Biol. 2012;32:242-250.

39. Prasad S, Mingrino R, Kaukinen K, et al. Inflammatory processes have differential effects on claudins 2,3 and 4 in colonic epithelial cells. Lab Invest. 2005;85:1139-1162.

40. Wardill HR, Bowen JM. Chemotherapy-induced mucosal barrier dysfunction: an updated review on the role of intestinal tight junctions. Curr Opin Support Palliat Care. 2013;7:155-161.

41. Brenchley JM, Douek DC. Microbial translocation across the GI tract. Ann Rev Immunol. 2012;30:149-173.

42. Watson CJ, Hoare CJ, Garrod DR, et al. Interferon-gamma selectively increases epithelial permeability to large molecules by activating different populations of paracellular pores. J Cell Sci. 2005; 118:5221-5230.

43. Hedl M, Li J, Cho JH, Abraham C. Chronic stimulation of Nod2 mediates tolerance to bacterial products. Proc Natl Acad Sci USA. 2007;104:19440-19445.

44. Glocker EO, Kotlarz D, Boztug K, et al. Inflammatory bowel disease and mutations affecting the interleukin-10 receptor. $N$ Engl J Med. 2009;361:2033-2045.

45. Duerr RH, Taylor KD, Brant SR, et al. A genome-wide association study identifies IL23R as an inflammatory bowel disease gene. Science. 2006;314:1461-1463.

46. Yoo D, Lo W, Goodman S, et al. Interferon-gamma downregulates ion transport in murine small intestine cultured in vitro. Am J Physiol Gastrointest Liver Physiol. 2000;279:G1323-G1332.

47. Garcia-Herrera J, Marca MC, Brot-Laroche E, et al. Protein kinases, TNF-\{alpha $\}$, and proteasome contribute in the inhibition of fructose intestinal transport by sepsis in vivo. Am J Physiol Gastrointest Liver Physiol. 2008;294:G155-G164.

48. Pérez-Bosque A, Amat C, Polo J, et al. Spray-dried animal plasma prevents the effects of Staphylococcus aureus enterotoxin $\mathrm{B}$ on intestinal barrier function in weaned rats. $J$ Nutr. 2006;136:2838-2843.

49. Demas GE, Chefer V, Talan MI, Nelson RJ. Metabolic costs of mounting an antigen-stimulated immune response in adult and aged C57BL/6J mice. Am J Physiol. 1997;273:R1631-R1637.

50. Johnson RW. Inhibition of growth by pro-inflammatory cytokines: an integrated view. J Anim Sci. 1997;75:1244-1255.

51. Nucera G, Gabrielli M, Lupascu A, et al. Abnormal breath tests to lactose, fructose and sorbitol in irritable bowel syndrome may be explained by small intestinal bacterial overgrowth. Aliment Pharmacol Ther. 2005;21:1391-1395.
52. Varcoe R, Haliday D, Tavill AS. Utilization of urea nitrogen for albumin synthesis in the stagnant loop syndrome. Gut. 1974;15:898-902.

53. Wanitschke R, Ammon HV. Effects of dihydroxy bile acids and hydroxy fatty acids on the absorption of oleic acid in the human jejunum. J Clin Invest. 1978;61:178-186.

54. Saito YA. The role of genetics in IBS. Gastroenterol Clin N Am. 2011;40:45-67.

55. Wong BS, Camilleri M, Carlson $\mathrm{P}$, et al. Increased bile acid biosynthesis is associated with irritable bowel syndrome with diarrhea. Clin Gastroenterol Hepatol. 2012;10:1009-1015.

56. Lupton JR. Microbial degradation products influence colon cancer risk: the butyrate controversy. J Nutr. 2004;134:479-482.

57. Bird JJ, Brown DR, Mullen AC, et al. Helper T cell differentiation is controlled by the cell cycle. Immunity. 1998;9:229-237.

58. Peng L, He Z, Chen W, et al. Effects of butyrate on intestinal barrier function in a Caco-2 cell monolayer model of intestinal barrier. Pediatr Res. 2007;61:37-41.

59. Fukuda S, Toh H, Hase K, et al. Bifidobacteria can protect from enteropathogenic infection through production of acetate. Nature. 2011;469:543-547.

60. Walker A. Breast milk as the gold standard for protective nutrients. J Pediatr. 2010;156:S3-S7.

61. Development Petherick A. Mother's milk: a rich opportunity. Nature. 2010;468:S5-S7.

62. Stockinger S, Hornef MW, Chassin C. Establishment of intestinal homeostasis during the neonatal period. Cell Mol Life Sci. 2011;68:3699-3712.

63. Morel PCH, Shollum LM, Buwalda TR. Digestibility of bovine immunoglobulin in the piglet. Manipulating Pig Production. In: Hennesey DP, Cranwell PD (eds) Proceedings of the Fifth Biennial Conference of the Australasian Pig Science Association (APSA), Canberra, ACT; 1995. p. 181.

64. Rodriguez C, Blanch F, Romano V, et al. Porcine immunoglobulins survival in the intestinal tract of adult dogs and cats fed dry food kibbles containing spray-dried porcine plasma (SDPP) or porcine immunoglobulin concentrate (PIC). Anim Feed Sci Technol. 2007;139:201-211.

65. Hanning RM, Drew M. Bovine immunoglobulin feeding trial. 1994 (data on file).

66. Begin F, Santizo MC, Peerson JM, et al. Effects of bovine serum concentrate, with or without supplemental micronutrients, on the growth, morbidity, and micronutrient status of young children in a low-income, peri-urban Guatemalan community. Eur J Clin Nutr. 2008;62:39-50.

67. Lembcke JL, Peerson JM, Brown KH. Acceptability, safety, and digestibility of spray-dried bovine serum added to diets of recovering malnourished children. J Pediatr Gastroenterol Nutr. 1997;25:381-384.

68. Peace RM, Campbell J, Polo J, et al. Spray-dried porcine plasma influences intestinal barrier function, inflammation, and diarrhea in weaned pigs. $J$ Nutr. 2011;141:1312-1317.

69. Detzel CJ, Horgan A, Henderson AL, et al. Development of a coculture model of the intestinal epithelium to study barrier function and immune exclusion by bovine IgG. J Parenter Enteral Nutr. 2014;38:146.127.

70. Corl BA, Harrell RJ, Moon HK, et al. Effect of animal plasma proteins on intestinal damage and recovery of neonatal pigs infected with rotavirus. J Nutr Biochem. 2007;18:778-784.

71. Bosi P, Casini L, Finamore A, et al. Spray-dried plasma improves growth performance and reduces inflammatory status of weaned pigs challenged with enterotoxigenic Escherichia coli K88. J Anim Sci. 2004;82:1764-1772.

72. Moretó M, Miró L, Maijó M, et al. Dietary supplementation with porcine plasma proteins reduce lymphocyte recruitment and 
cytokine and chemokine expression in a mouse model of spontaneous colitis. Gastroenterology. 2010;138:S-743.W1801.

73. Jiang H, Becker C, Przybyszewski J, MacDonald RS. Dietary immunoglobulins affect colon cytokines in mouse model of inflammatory bowel disease. FASEB J. 2010;24:720.1.

74. Pérez-Bosque A, Miró L, Polo J, et al. Dietary plasma protein supplements prevent the release of mucosal proinflammatory mediators in intestinal inflammation in rats. $J$ Nutr. 2010;140:25-30.

75. Pérez-Bosque A, Miró L, Polo J, et al. Dietary plasma proteins modulate the immune response of diffuse gut-associated lymphoid tissue in rats challenged with Staphylococcus aureus enterotoxin B. J Nutr. 2008;138:533-537.

76. Weaver EM, Klein GL, DeVries BK, et al. Endotoxin Neutralization activity (ENA) of bovine plasma and bovine Immunoglobulin ( $\operatorname{IgG}$ )-rich fractions as compared to human plasma. FASEB J. 2013;27:1079.58.

77. Navarro A, Eslava C, Garcia de la Torre G, et al. Common epitopes in LPS of different Enterobacteriaceae are associated with an immune response against Escherichia coli 0157 in bovine serum samples. J Med Microbiol. 2007;56:1447-1454.
78. Asmuth DM, Stombaugh J, Ma ZM, et al. Changes in stool microbiota, bacterial translocation and mucosal immunity after oral serum-derived bovine immunoglobulin (SBI) administration. In: 20th Conference on Retroviruses and Opportunistic Infections (CROI); Mar 3-6; Atlanta, GA; 2013.

79. Asmuth DM, Ursell L, Ma ZM, et al. Duodenal lamina propria CD4+ T-lymphocyte (CD4+ LPL) increases following oral serum-derived bovine immunoglobulin (SBI) administration leads to reduced enterocyte damage and improved collagen turnover in HIV-enteropathy. Presented at Interscience Conference on Antimicrobial Agents and Chemotherapy (ICAAC); 2013.

80. Ley RE, Turnbaugh PJ, Klein S, Gordon JI. Microbial ecology: human gut microbes associated with obesity. Nature. 2006;444: $1022-1023$.

81. Arumugam M, Raes J, Pelletier E, et al. Enterotypes of the human gut microbiome. Nature. 2011;473:174-180.

82. Corthesy B. Multi-faceted functions of secretory $\operatorname{IgA}$ at mucosal surfaces. Front Immunol. 2013;4:185. 